Check for updates

Cite this: J. Mater. Chem. B, 2018, 6, 7943

Received 20th September 2018, Accepted 26th October 2018

DOI: $10.1039 / c 8 t b 02483 a$

rsc.li/materials-b

\section{Enzymatic synthesis of a thiolated chitosan-based wound dressing crosslinked with chicoric acid}

\author{
Ivaylo Stefanov, ${ }^{a}$ Dolores Hinojosa-Caballero, ${ }^{b}$ Santiago Maspoch, (D) ${ }^{c}$ \\ Javier Hoyo (D) and Tzanko Tzanov (D)*a
}

\begin{abstract}
This work describes the enzymatic synthesis of multifunctional hydrogels for chronic wound treatment using thiolated chitosan and the natural polyphenol chicoric acid. Gelation was achieved by laccasecatalyzed oxidation of chicoric acid, a natural compound used for the first time as a homobifunctional crosslinker, reacting subsequently with nucleophilic thiol and amino groups from the chitosan derivative. This approach allowed for twice as fast gelation at a three-fold reduced crosslinking reagent concentration, compared to reported enzymatic synthesis of hydrogels using gallic acid as a phenolic provider. Hydrogels with $600 \%$ swelling capacity, coupled with only 20\% weight loss after 6 days under physiological conditions, were obtained. The clinically relevant Gram-positive Staphylococcus aureus and the Gram-negative Pseudomonas aeruginosa were reduced by up to 4.5 and 5.5 logs, respectively. A tunable, in the range of 20-95\%, ex vivo inhibition of myeloperoxidase (MPO) activity in chronic wound exudate was achieved, together with control over the total matrix metalloproteinase (MMP) activities.
\end{abstract}

\section{Introduction}

When a wound remains in the inflammatory phase, delaying its normal physiological healing, the wound becomes a chronic or non-healing one. ${ }^{1}$ In the majority of cases, venous stasis and ischemia, secondary to diabetes mellitus and pressure, define the etiology of non-healing ulcers. ${ }^{2}$ Incidences with chronic wounds are increasing annually due to the demographic rise of the elderly population and the increased number of diabetes cases. Non-healing wounds cause pain and discomfort to patients, deteriorate their quality of life and in addition are prone to severe bacterial infections. Infection-related complications of chronic wounds might ultimately result in limb amputation and even death. The dynamics of the pathological processes of chronic wounds are related to different factors, contributing to wound chronicity. Bacterial contamination stimulates the inflammatory response, which leads to overproduction of macrophages and neutrophils. ${ }^{3}$ These immune cells carry matrix metalloproteinases (MMPs) and reactive oxygen species (ROS), necessary to cleanse the wound of cellular debris and to protect from bacterial biofilms. ${ }^{4}$ MMPs are zinc-dependent proteases, which are able to degrade collagen and elastin - the structural units of

\footnotetext{
${ }^{a}$ Grup de Biotecnologia Molecular i Industrial (GBMI), Department of Chemical Engineering, Universitat Politècnica de Catalunya - (UPC), Rambla Sant Nebridi, 22, 08222 Terrassa, Barcelona, Spain. E-mail: tzanko.tzanov@upc.edu

${ }^{b}$ Unitat de Ferides Complexes, Consorci Sanitari de Terrassa Hospital de Terrassa, Ctra. Torrebonica, s/n, 08227 Terrassa, Barcelona, Spain

${ }^{c}$ Department of Analytical Chemistry, Universitat Autónoma de Barcelona,

08193 Bellaterra, Barcelona, Spain
}

the extracellular matrix (ECM). ${ }^{5}$ The molecular basis of wound chronicity relies on excessive proteolysis of collagen, elastin, growth factors and tissue inhibitors of MMPs (TIMP). ${ }^{6}$ Additionally, the hypochlorous acid ( $\mathrm{HClO}$ ) produced by the neutrophil-derived myeloperoxidase (MPO) can oxidize biomolecules, such as DNA, proteins and lipids. ${ }^{7,8}$

There is an increasing demand for adequate and efficient therapies and dressings to boost the normal wound healing process. An ideal wound dressing should absorb and retain the excess of exudate away from the wound bed, maintaining at the same time the moist environment necessary for wound healing. ${ }^{9}$ Hydrogels featuring these properties dominate nowadays the market of chronic wound dressings. ${ }^{10}$

The multifactorial nature of chronic ulcers often turns many single-factor directed approaches into ineffective or low efficacy therapies. Our concept is based on creating multifunctional bioactive and biocompatible hydrogels, which will address simultaneously specific chronic wound constituents in order to promote the normal wound healing process. Control of overexpressed MMPs and MPO may prevent excessive degradation of the ECM and diminish the oxidative stress. Providing an antibacterial environment to the wound will protect it from infection. Combining several properties beneficial for the healing process in a dressing material would result in more effective chronic wound treatment.

Chitosan is a hydrophilic and antibacterial polysaccharide derived from the outer shell of crustaceans or from fungal origin, which is known to support the wound healing process. ${ }^{11}$ Fungal chitosan has superior chemical and physicochemical 
properties, such as a high degree of purity and a controllable degree of acetylation and molecular weight. In addition, fungal chitosan has lower immunogeneicity, compared to the crustacean counterpart, and thus is preferred for medical applications. Chitosan-based hydrogels have been applied in tissue engineering, regenerative medicine, drug delivery and wound healing. ${ }^{12}$ In most of these applications, however, the poor mechanical properties of chitosan-based hydrogels imply their chemical crosslinking, often producing toxic residues of crosslinkers that are unreacted and difficult to remove traces of, such as glutaraldehyde, ethyleneglycol diglycidylether and isocyanate. ${ }^{13}$ In the current study, we use thiol derivatives of chitosan targeting a dual beneficial impact on the properties of the resulting materials. On one hand, the thiol groups can be oxidized to disulfide bridges, which will enhance the stability of the hydrogels. On the other hand, the thiol functionalities may provide inhibition of the overexpressed deleterious wound enzymes, i.e. MPO by both scavenging $\mathrm{HClO}$ and interfering in the catalytic cycle of the enzyme ${ }^{14,15}$ and MMPs by chelation of $\mathrm{Zn}^{2+}$ from the enzyme active center. ${ }^{16}$

Replacing the harsh chemical crosslinkers with naturallybased ones which can be oxidized by environmentally friendly enzymatic reactions is a promising strategy employed in our group to develop chemically crosslinked hydrogels for wound healing. Enzymes like tyrosinase, horseradish peroxidase and laccase are able to oxidize different polyphenolic substrates. Among these oxidative enzymes, laccase is characterized by low specificity and appears suitable for green chemistry synthesis, using only atmospheric oxygen as a co-factor. ${ }^{17}$ Chicoric acid (ChA), a derivative of caffeic and tartaric acid, is a natural phenolic compound extracted from Echinacea plants. ${ }^{18}$ Only few papers report the implication of ChA in medicine and its potentially beneficial properties for treatment of diabetes. ${ }^{19,20}$ In addition, ChA possesses anti-hyaluronidase activity, acts as an immunostimulator and protects collagen from free-radical induced degradation, ${ }^{21}$ features which could ultimately enhance the wound healing process. The chemical structure of ChA, consisting of two phenolic residues separated by an eightcarbon chain, defined the choice of this polyphenolic acid. The terminal phenolic groups can be oxidized by laccase to highly reactive quinones that further undergo Michael addition or Schiff base reactions with nucleophilic amino and thiol groups. In our recent work, it was found that the gel crosslinking was mainly due to the Michael addition between the thiol groups of modified chitosan and the oxidized polyphenols. ${ }^{22}$ Thiol Michael addition has been used also for synthesis of other biopolymer-based hydrogels for wound healing. ${ }^{23,24}$ To the best of our knowledge, ChA has never been used as a crosslinker for enzymatic synthesis of hydrogels, whereas its eight-carbon spacer arm can improve the flexibility of the hydrogel material. ${ }^{25}$ Polyphenol-loaded chitosan-based hydrogels produced in our group have shown promising results as bioactive wound dressing platforms. ${ }^{22,26,27}$ Combining thiolated chitosan (TCS) with ChA is expected to improve the stability of the hydrogel and its inhibitory activity over wound MMPs and MPO. The aim of this work is to synthesize a bioactive hydrogel able to address the multifactorial nature of chronic wounds in order to support the normal wound healing process. The resulting hydrogels should possess tunable rheological properties, coupled with the ability to control the MMP and MPO activities, and provide a bacteriafree environment for the wound. The present work suggests a novel chitosan-based engineered material, which provided improved bioactivity and rheological performance of the hydrogels, compared to our recently published work, as a prerequisite for in vivo studies.

\section{Results and discussion}

\subsection{Enzymatic synthesis of hydrogels}

In this study, fungal chitosan was chosen as a material for hydrogel preparation, due to its reduced immunological reactions, compared to that from crustacean origin. A higher degree of deacetylation, i.e. a higher amount of amino groups, provides better solubility for chitosan preparations and increases the cationic character of the polymer, resulting in stronger antibacterial activity. ${ }^{28}$ A thiolated derivative of chitosan was achieved by a chemical reaction between chitosan amino groups and 2-iminothiolane hydrochloride (Traut's reagent). ${ }^{29}$ The chitosan:Traut's ratio determines the amount of free thiol groups (Table 1) in the thiolated chitosan (TCS) samples.

TCS/ChA hydrogels were prepared by laccase-assisted oxidation of ChA in a one-step reaction. Controls with the same reagent composition, but omitting laccase or ChA, gelated after at least $8 \mathrm{~h}$. The gelation of controls was due to the formation of disulfide bridges, as described in the pioneering study about chitosan thiolation. ${ }^{29}$ The control prepared from non-thiolated chitosan, ChA and laccase did not gelate even after $24 \mathrm{~h}$ of incubation. These observations were in agreement with our initial hypothesis that the gel formation would result mainly from the covalent interactions between oxidized polyphenols and thiol groups from TCS, while the non-modified amino groups of chitosan have a minor contribution. ${ }^{22}$ The polyphenolic ChA oxidized by laccase crosslinks TCS acting as a homobifunctional crosslinker (Scheme 1). ${ }^{30}$

A similar mechanism of formation of quinone-thiol adducts between rosmarinic acid (a structural analogue of ChA) and cysteine was proposed by Tang et al. ${ }^{31}$ Laccases were also utilized for the synthesis of organic compounds, by oxidation of polyphenols to quinones, which subsequently undergo nonenzymatic Michael addition reaction with thiols through thioether bonds. ${ }^{32}$ Similarly, in our case, the laccase oxidizes the polyphenolic moieties of ChA to highly reactive quinones, which further react with the nucleophilic - $\mathrm{SH}$ group from TCS to achieve the crosslinking and gelation of the material.

Table 1 Thiolated chitosan (TCS) samples

\begin{tabular}{lll}
\hline Sample code & $\begin{array}{l}\text { Reaction ratio } \\
\text { chitosan : Traut's }\end{array}$ & $\begin{array}{l}\mu \text { mol free }-\mathrm{SH} \\
\text { per g polymer }\end{array}$ \\
\hline TCS1-10 & $10: 1$ & $212.5 \pm 9.8$ \\
TCS1-5 & $5: 1$ & $372.5 \pm 23$ \\
TCS2-5 & $5: 2$ & $502.7 \pm 29.6$
\end{tabular}




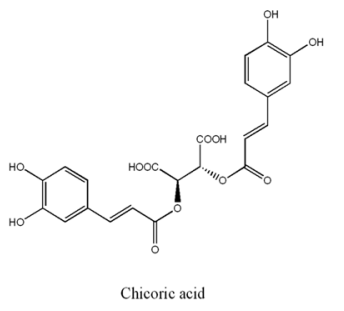
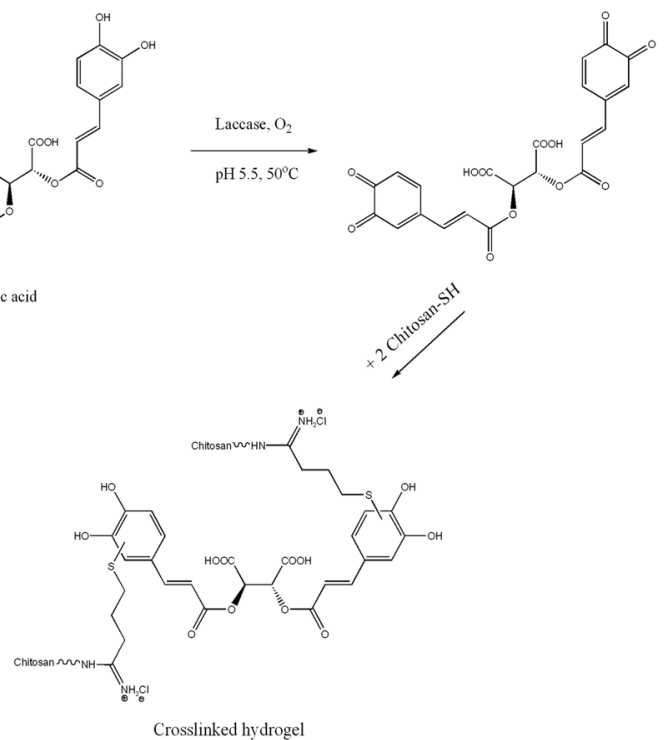

Scheme 1 Schematic representation of the laccase-assisted hydrogel formation between TCS and ChA. The one-step hydrogel synthesis can be subdivided into two consequent reactions. In the first reaction, phenolic groups of ChA are oxidised by laccase, yielding quinone derivatives. In the second reaction, two molecules of TCS are chemically crosslinked through Michael-addition reaction of nucleophilic thiol groups and quinone moieties.

The molar ratios between the thiol groups of chitosans with different degrees of thiolation and various concentrations of ChA are shown in Table 2. The evolution of the enzymaticallyinitiated formation of TCS/ChA hydrogels was analyzed with time sweep rheological tests (Fig. 1).

The crossover of the storage $\left(G^{\prime}\right)$ and loss $\left(G^{\prime \prime}\right)$ moduli, defined as the gelation point (GP), occurred after different reaction times, depending on the degree of thiolation of chitosan. When using TCS1-10 (the chitosan sample with the lowest thiolation degree), the GP was reached after $1200 \mathrm{~s}$, while $1080 \mathrm{~s}$ were necessary to gelate the sample prepared with TCS1-5. In all cases, $G^{\prime}$ continued rising beyond the GP and reached values of 4 and $53 \mathrm{~Pa}$ after $1800 \mathrm{~s}$ for $0.73 \mathrm{TCS} 1-10$ and 0.73TCS1-5, respectively (Fig. 1A and B). By contrast, the hydrogel with the highest degree of thiolation 0.73TCS2-5 gelated within $420 \mathrm{~s}$ and its $G^{\prime}$ value reached $115 \mathrm{~Pa}$ after $1800 \mathrm{~s}$ (Fig. 1C). These observations logically suggest that using a higher degree of chitosan

Table 2 Samples of thiolated chitosan/chicoric acid hydrogels, obtained upon reaction with laccase

\begin{tabular}{llll}
\hline Sample code & $\begin{array}{l}\text { Thiolated } \\
\text { chitosan }\end{array}$ & $\begin{array}{l}\text { Chicoric } \\
\text { acid }(\mathrm{mM})\end{array}$ & $\begin{array}{l}\text { Molar ratio thiol } \\
\text { groups : ChA }\end{array}$ \\
\hline 0.24TCS1-10 & TCS1-10 & 0.24 & 47.6 \\
0.49TCS1-10 & TCS1-10 & 0.49 & 23.4 \\
0.73TCS1-10 & TCS1-10 & 0.73 & 15.7 \\
0.24TCS1-5 & TCS1-5 & 0.24 & 83.6 \\
0.49TCS1-5 & TCS1-5 & 0.49 & 41 \\
0.73TCS1-5 & TCS1-5 & 0.73 & 27.5 \\
0.24TCS2-5 & TCS2-5 & 0.24 & 112.8 \\
0.49TCS2-5 & TCS2-5 & 0.49 & 55.3 \\
0.73TCS2-5 & TCS2-5 & 0.73 & 37.1
\end{tabular}
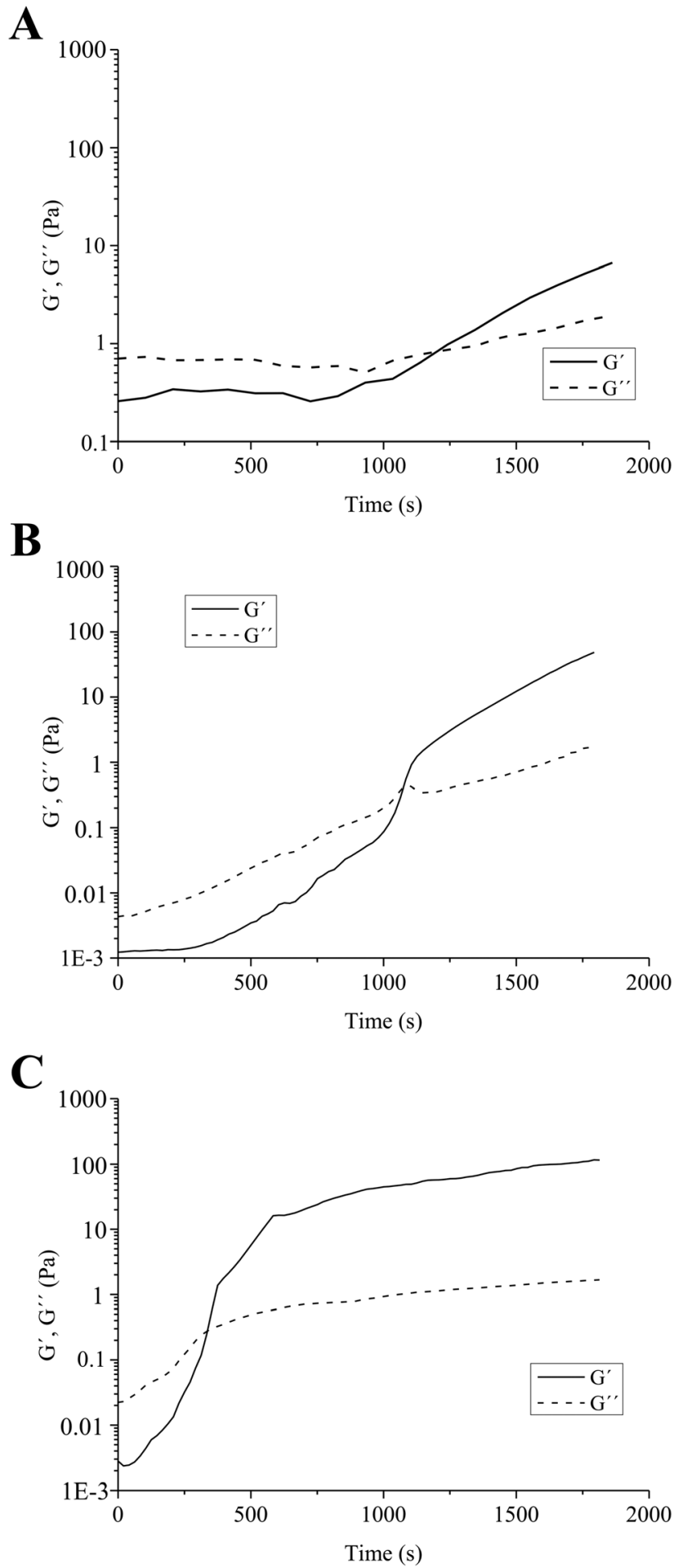

Fig. 1 Time sweep rheological characterization of the hydrogels. Evolution of the storage $\left(G^{\prime}\right)$ and loss $\left(G^{\prime \prime}\right)$ moduli vs. time at $50{ }^{\circ} \mathrm{C}$ of hydrogels, prepared with the highest degree of thiolation and the same concentration of ChA in the presence of laccase $\left(2.7 \mathrm{U} \mathrm{mL}^{-1}\right)$, (A) 0.73TCS1-10, (B) 0.73TCS1-5 and (C) $0.73 T C S 2-5$.

thiolation would lead to shorter gelation time and higher $G^{\prime}$ value. The latter can be interpreted as more solid-like behavior and higher mechanical strength of the 0.73TCS2-5 hydrogel. 


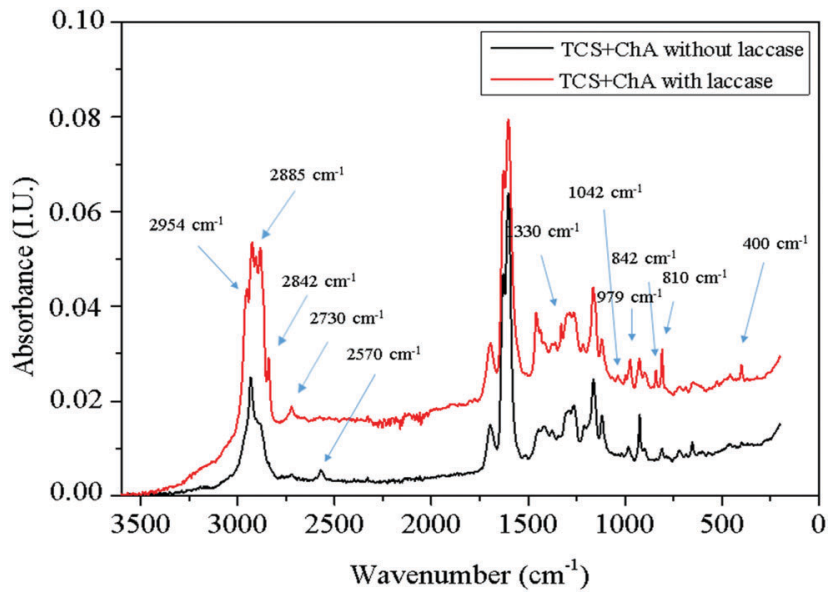

Fig. 2 Raman spectra of a TCS:ChA $(5: 1 \mathrm{w} / \mathrm{w})$ mixture prepared from TCS with the highest degree of thiolation, in the presence or absence of laccase. In order to achieve comparable peaks, a higher concentration of ChA and hence a lower ratio of TCS: ChA was used.

Similar dependence of the gelation time on the degree of thiolation was observed in our previous work, however, herein both the concentration of the crosslinking agent and gelation time were reduced. ${ }^{22}$ The overall low $G^{\prime}$ values of the hydrogels may match the mechanical strength of soft tissues, which eventually will improve the dressing comfort.

The Raman spectra of lyophilized hydrogels did not apparently reveal the crosslinking mechanism, presumably due to the high mass ratio of TCS : ChA. Thus, in order to elucidate the mechanism of hydrogel formation, a mixture with lower TCS: ChA ratio $(5: 1 \mathrm{w} / \mathrm{w})$ in the presence and absence of laccase was studied. The mixtures were incubated for $2 \mathrm{~h}$ at $50{ }^{\circ} \mathrm{C}$ and then the freeze-dried specimens were studied by Raman spectroscopy (Fig. 2).

A peak at $2570 \mathrm{~cm}^{-1}$ related to the thiol groups in TCS appeared in the spectrum of the material prepared without laccase. This peak was not present in the spectrum of TCS : ChA reacted with laccase, confirming the consumption of the thiol groups. The formation of a thioether bond $-\mathrm{CH}_{2} \mathrm{~S}$ - between the thiol groups and the ChA oxidized by laccase through the Michael addition reaction is supported by the appearance of new peaks at $2730,2842,2885$ and $2954 \mathrm{~cm}^{-1}$ due to symmetric and asymmetric $-\mathrm{CH}_{2}-$ stretching, respectively. The peak at $1330 \mathrm{~cm}^{-1}$ was due to wagging vibrations of $-\mathrm{CH}_{2}$ groups, while increased intensity of the peak at $810 \mathrm{~cm}^{-1}$ can be associated with C-S stretching of newly formed thioether bonds. The peaks at 842 and $979 \mathrm{~cm}^{-1}$ can be assigned to different skeletal vibrations, and the peak at $1042 \mathrm{~cm}^{-1}$ was due to the ring vibrations with $\mathrm{C}-\mathrm{S}$ interaction of the ChA aromatic cores. ${ }^{33}$

\subsection{Morphology of the hydrogels}

Cryo-SEM images of cross-sectional hydrogels (Fig. 3) revealed porous structures with interconnected, randomly distributed pores with varying size and shape, depending on the concentration of ChA. The hydrogel prepared with the lowest concentration of ChA (0.24TCS2-5) showed the largest pore size and
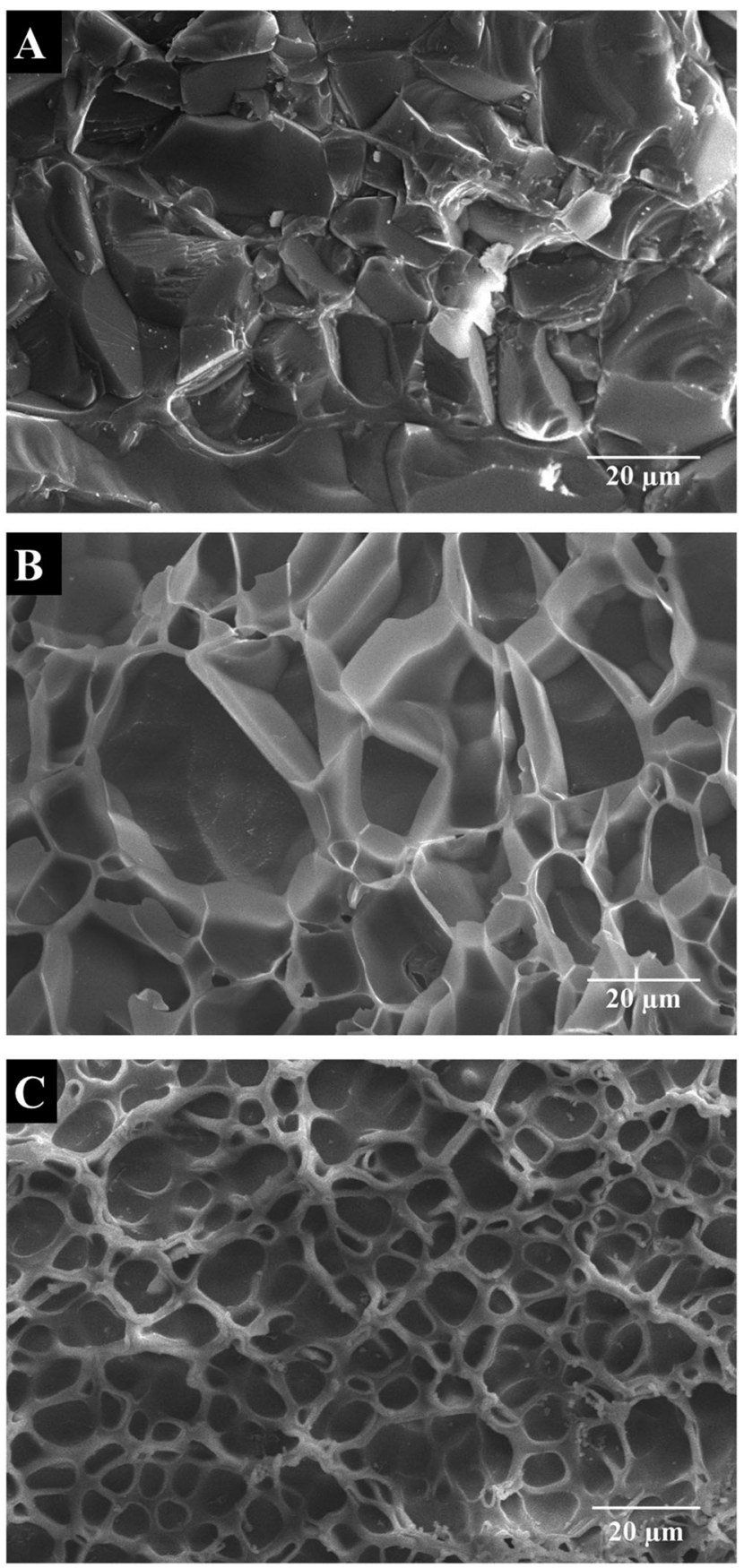

Fig. 3 SEM images of lyophilized hydrogels, prepared with TCS2-5 and different concentrations of ChA: (A) 0.24TCS2-5; (B) 0.49TCS2-5; and (C) 0.73 TCS2-5. Magnification $\times 1000$. At least twenty pores per each SEM image were taken into account for the calculation of the hydrogel average pore size.

broader size distribution with an average diameter of $22.0 \pm$ $8.5 \mu \mathrm{m}$ (Fig. 3A). Increasing the amount of ChA lead to a denser network and therefore to a smaller pore size and narrower size distribution with an average diameter of $18.4 \pm 6.1$ and $6.5 \pm 2.2 \mu \mathrm{m}$ for $0.49 \mathrm{TCS} 2-5$ and $0.73 \mathrm{TCS} 2-5$ hydrogels, respectively (Fig. 3B and C). Tunability of the network density of hydrogels may define their usefulness in controlled drug delivery applications. 


\subsection{Swelling properties of the hydrogels}

The amount of water or physiological fluid absorbed and retained in the hydrogel matrix is directly related to the degree of its crosslinking. Highly crosslinked hydrogels will absorb less, while networks with low crosslinking density will absorb higher volumes of wound fluid. The capacity of the gel to retain liquids, however, should not compromise its mechanical integrity. In acute wounds, the role of exudate is to facilitate the diffusion of growth and immune factors and the migration of fibroblasts across the wound bed. Chronic wounds, however, are often characterized by producing large amounts of exudate. Effective exudate management can improve the overall healing process and the patient outcome. ${ }^{34}$ Therefore, according to the concept of 'moist wound healing', the dressing should be able to absorb the exudate and thus prevent the excessive degradation of ECM, while maintaining the moisture of the wound. ${ }^{35}$ On the other hand, the $\mathrm{pH}$ of a chronic wound may vary, depending on the type and stage of the wound, and can affect different factors, participating in the healing process. ${ }^{36}$ Thus, the swelling behavior of the hydrogels as a function of the $\mathrm{pH}$ of the medium was studied (Fig. 4).

At lower $\mathrm{pH}$ values the concentration of charged ionic groups $\left(\mathrm{NH}_{3}{ }^{+}\right)$in the hydrogels increases, increasing the osmotic pressure and charge repulsion. This phenomenon leads to higher swelling capacity of the hydrogels. However, at higher $\mathrm{pH}$ values, due to the deprotonation of the amino groups of chitosan, their swelling capacity significantly decreased. ${ }^{12}$ The higher degree of crosslinking explains the lower swelling capacity of the hydrogels, prepared with higher concentration of ChA.

Moreover, since the nonoxidized polyphenols can be oxidized and subsequently polymerized at alkaline $\mathrm{pH}$ values, ${ }^{37}$ the hydrogel structure can be additionally crosslinked, resulting in less swelling capacity. On the other hand, thiol groups can be also additionally oxidized at alkaline $\mathrm{pH}$, leading to more crosslinked structures with lower swelling capacity. ${ }^{38}$

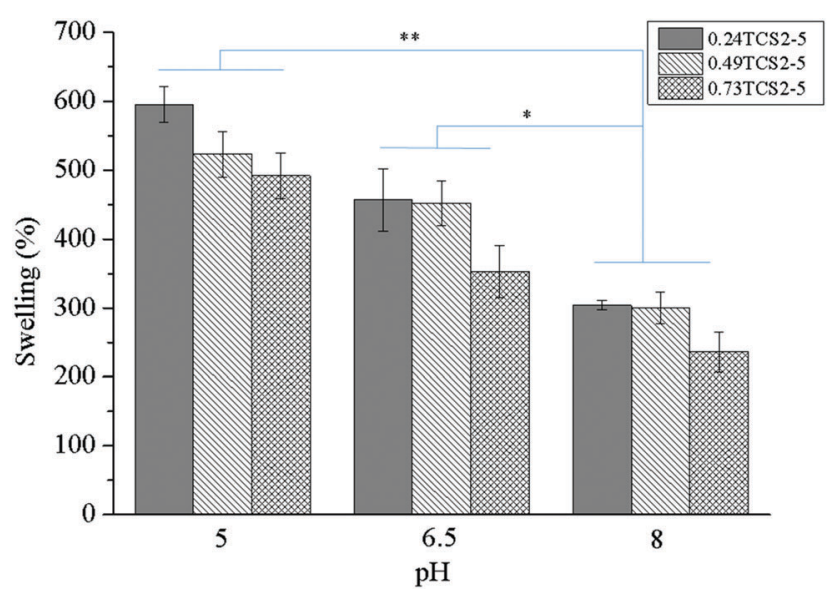

Fig. 4 Swelling behavior of hydrogels prepared from TCS2-5 and varying the concentration of $\mathrm{ChA}$ at different physiological pHs. The results are reported as mean values \pm SD $(n=5)$ and their statistical significance was calculated using one-way ANOVA $(p<0.05)$.
Appropriate management of wound exudate may diminish chronic wound exacerbation, enhancing the healing process. Heavily exuding wounds should be treated with highly absorbent materials, preventing healthy skin maceration and excoriation and reducing the frequency of dressing change. ${ }^{39}$ Wound fluids collected from chronic wounds with various etiology and in different stages have shown distinct $\mathrm{pH}$, most commonly around $5-8 .^{36}$ Despite possessing high absorptive capacity (240-300\%) at $\mathrm{pH}=8$, the hydrogels will be saturated faster. Contrastingly, at $\mathrm{pH}=5$, more time will be needed for hydrogel saturation, due to their higher swelling capacity (500-600\%), reducing the frequency of wound dressing change. Therefore, the hydrogels will be more efficient in exudate management for chronic wounds with lower $\mathrm{pH}$.

\subsection{Radical scavenging activity}

Reactive oxygen species (ROS) play an integral role in host defense, and hence in wound healing. However, elevated levels of ROS lead to oxidative stress and can have a detrimental effect on the proper healing process. ${ }^{40}$ The antioxidant activity of the natural polyphenol ChA is well documented. ${ }^{41,42}$ In addition, the residual free thiol groups in the hydrogel matrix can also act as antioxidants and radical scavengers. ${ }^{43}$ Moreover, an enhanced effect of the thiol groups on the antioxidant performance of the polyphenolic compounds might be expected. ${ }^{44}$ The radical scavenging effect of the hydrogels in the presence of DPPH (Fig. 5) depends on the degree of thiolation of chitosan and the amount of ChA. The highest antioxidant capacity, achieved with 0.73 TCS2-5 (around 15\%), was due to the ChA released from the hydrogel matrix. Low antioxidant activity of the hydrogels was most probably due either to complete oxidation of the phenolic groups present in ChA upon treatment with laccase or to the low concentration of the released non-oxidized ChA. This was not the case when gallic acid was used for crosslinking the hydrogels due to steric hindrance preventing all three phenol groups in gallic acid from oxidation. ${ }^{22}$

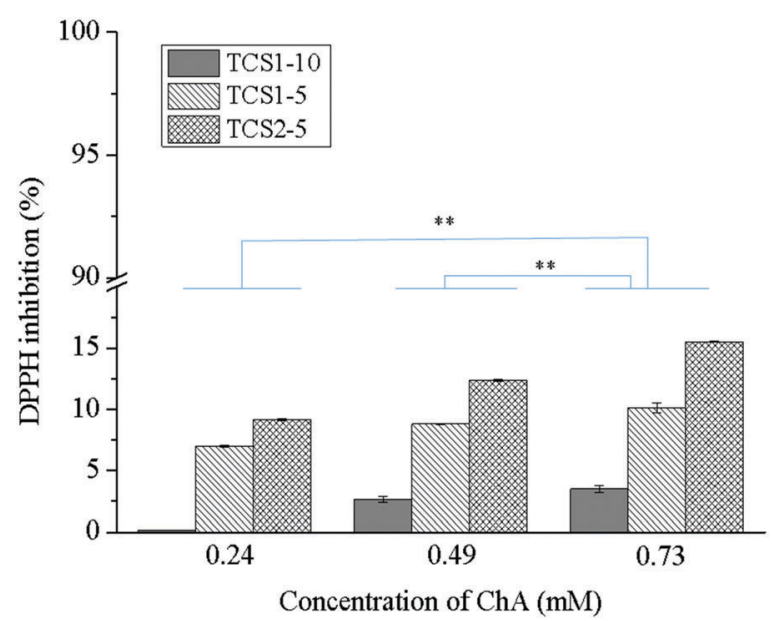

Fig. 5 Antioxidant activity of the hydrogels depending on the degree of chitosan thiolation and the concentration of ChA. The results are reported as mean values $\pm \mathrm{SD}(n=3)$ and their statistical significance was calculated using one-way ANOVA ( $p<0.05$ ). 


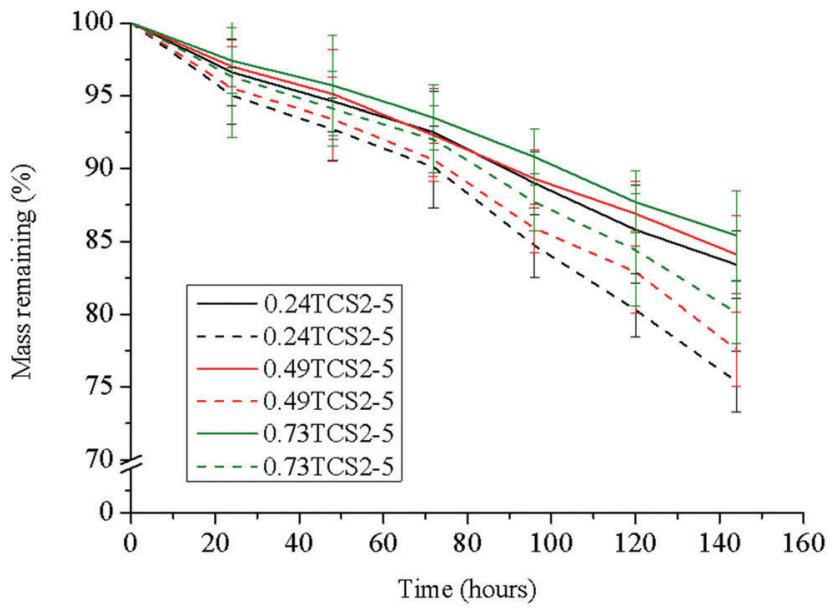

Fig. 6 Stability of hydrogels in PBS alone (continuous line) and in the presence of lysozyme (dashed line). The hydrogels were prepared with TCS2-5 and various ChA concentrations. The results are reported as mean values $\pm \mathrm{SD}(n=5)$ and their statistical significance was calculated using one-way ANOVA $(p<0.05)$.

\subsection{Biostability of the hydrogels}

The antibacterial enzyme lysozyme, commonly found in elevated levels in chronic wounds, ${ }^{45}$ cleaves the $\beta$-(1-4)-linkages between the $N$-acetylglucosamine and $N$-acetylmuramic acid in the cell membrane of bacteria. Lysozyme, however, is also able to hydrolyze the $\beta$-(1-4)-bond between the $N$-acetyl glucosamine and glucosamine units in chitosan. Thus, the biostability of chitosan-based hydrogels is an important characteristic for their prolonged, up to six days, exploitation as wound dressings. ${ }^{27}$ The tested hydrogels did not reveal significant differences in their degradation profile upon incubation for $144 \mathrm{~h}$ in PBS or in PBS with lysozyme (Fig. 6). The low susceptibility of sample 0.73 TCS2-5 to enzymatic hydrolysis was most probably due to the hindrance of the linkages susceptible to degradation in the crosslinked hydrogel structure. This was evidenced also with the samples 0.24TCS2-5 and 0.49TCS2-5, which degraded to a higher degree, due to the facilitated access of the enzyme to their chains. Another factor that may contribute to the enhanced biostability of the hydrogels is the degree of deacetylation (in our case 87\%) of chitosan. Chitosans with a higher degree of deacetylation, and respectively more amino groups, are less susceptible to lysozyme degradation. ${ }^{46}$ Most probably, this is due to electrostatic repulsion between the positively charged biopolymer and the enzyme protein. ${ }^{47}$ On the other hand, the slow degradation of the hydrogels defines the sustained release of polyphenols during incubation in physiological solution.

The hydrogel platform 0.73 TCS $2-5$ revealed a significantly improved biostability profile (over 15\% lesser weight loss) compared to our previously obtained material. ${ }^{22}$
A1

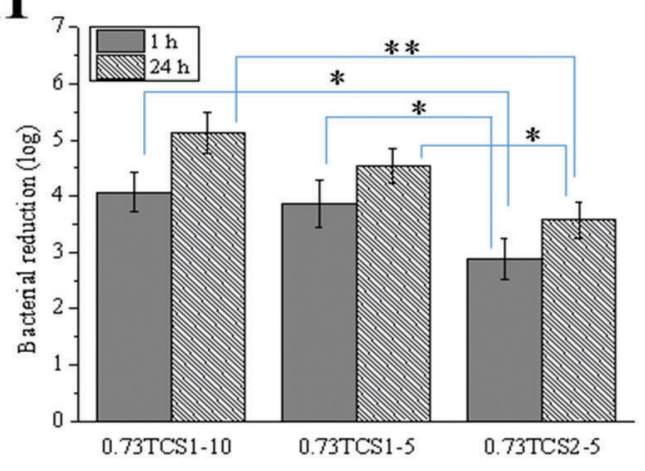

A2

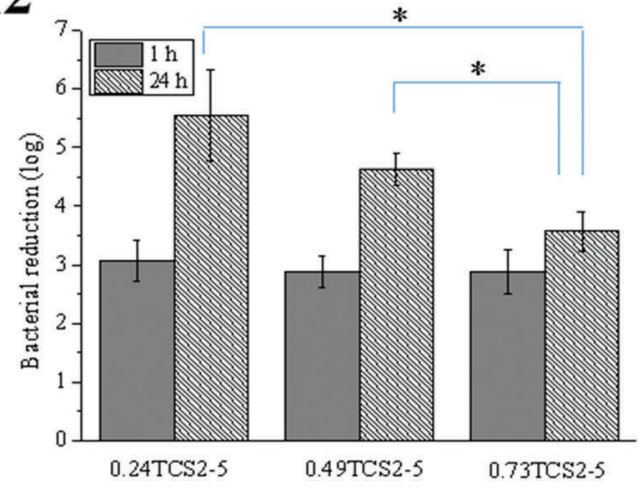

B1

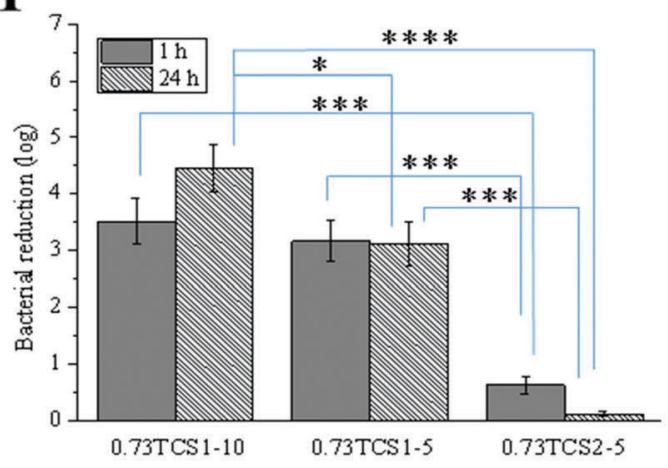

B2

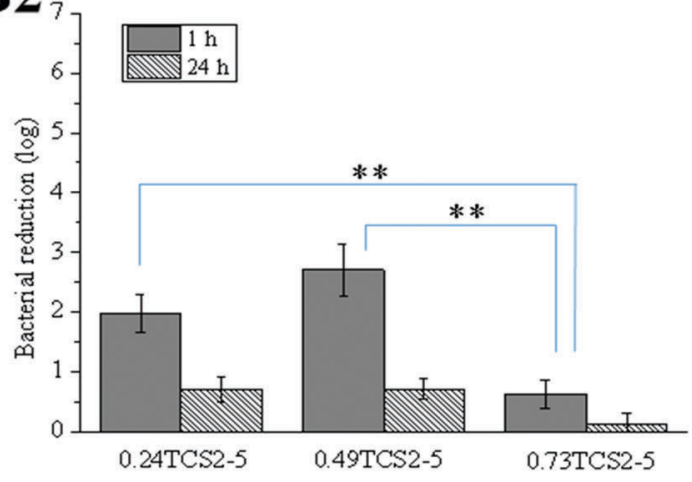

Fig. 7 Antibacterial activity of TCS/ChA hydrogels against: (A) Pseudomonas aeruginosa and (B) Staphylococcus aureus ((A1) and (B1)-hydrogels, prepared with the highest concentration of ChA and varying the degree of chitosan thiolation; (A2) and (B2)-hydrogels, prepared from chitosan with the highest degree of thiolation and varying the concentration of $\mathrm{ChA}$ ) as a function of the degree of chitosan thiolation and the concentration of ChA. The results are reported as mean values \pm SD $(n=3)$ and their statistical significance was calculated using one-way ANOVA $(p<0.05)$. 


\subsection{Antibacterial activity of the hydrogels}

The antibacterial activity of the hydrogels was assessed against the clinically relevant Gram-negative $P$. aeruginosa and Grampositive $S$. aureus. The growth of these strains was reduced to a different extent, depending on the degree of chitosan thiolation, concentration of ChA and time of incubation with the hydrogels (Fig. 7). In all cases, increasing the thiolation degree of chitosan affected negatively the antibacterial performance of the hydrogels. This was due to the consumption of the accessible $-\mathrm{NH}_{2}$ groups in chitosan, necessary for the disruption of the bacterial membrane, during the thiolation reaction and the enzyme-catalyzed crosslinking with ChA, where part of the amino groups can also undergo Michael addition or Schiff base reactions with the oxidized ChA. ${ }^{48}$ Zheng et al. have demonstrated that chitosan with low molecular weight has greater antibacterial activity against Gram-negative strains. ${ }^{49}$ Similarly, low molecular weight chitosan was used in the current work and this was most probably the reason for the better antibacterial performance of the hydrogels against $P$. aeruginosa compared to $S$. aureus.

\subsection{Ex vivo activity of the hydrogels against chronic wound enzymes}

MPO is an oxidative enzyme, released from human neutrophils upon certain external signals. This enzyme can be involved in two different catalytic cycles - oxidation and chlorination. During the chlorination cycle in the presence of $\mathrm{H}_{2} \mathrm{O}_{2}$ and $\mathrm{Cl}^{-}$ MPO catalyzes the generation of $\mathrm{HClO}$, the most potent bactericidal agent produced in humans. ${ }^{50}$ Despite its primary function to kill the invading pathogens, excessive amounts of HClO can contribute to disruption of the healing process by oxidizing different biomolecules. ${ }^{51}$ Thus, control over the MPO activity may promote the healing process. Recently, we demonstrated that polyphenols were able either to scavenge the already formed $\mathrm{HClO}$ or engage the MPO in the oxidation cycle, and thus inhibit its chlorination activity. ${ }^{52}$ The inhibitory activity of thiol groups against MPO has been also demonstrated. ${ }^{15}$ Surprisingly, the hydrogels prepared with higher concentration of the anti-oxidant ChA did not show higher inhibitory activity against MPO (Fig. 8A). This result might be related to the low concentration of ChA released from the crosslinked matrix. Contrarily, the hydrogels prepared with lower concentration of ChA revealed higher inhibitory activity against MPO, due to the higher amount of free thiol groups. Nevertheless, MPO inhibition tunable in the range of $20-95 \%$ for the different groups of hydrogels was achieved.

In acute wounds, MMPs are responsible for the cleavage of the highly crosslinked collagen in the wound bed, thereby allowing the migration of cells needed for the reepithelialization process. ${ }^{53}$ Elevated levels of MMPs, however, and a disturbed MMP/TIMP ratio can lead to excessive degradation of ECM, and thus chronicity of the wound. ${ }^{54}$ Thiolated derivatives of chitosan might inhibit MMPs by chelating $\mathrm{Zn}^{2+}$ from their active center. In addition, ChA with its two - $\mathrm{COOH}$ groups may electrostatically entrap the positively charged MMPs in the hydrogel matrix. ${ }^{16}$

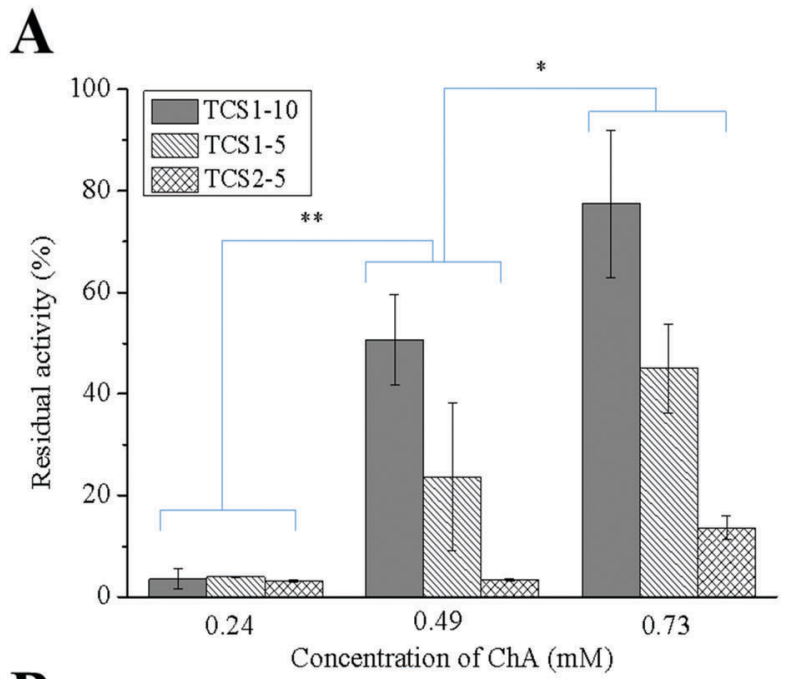

B

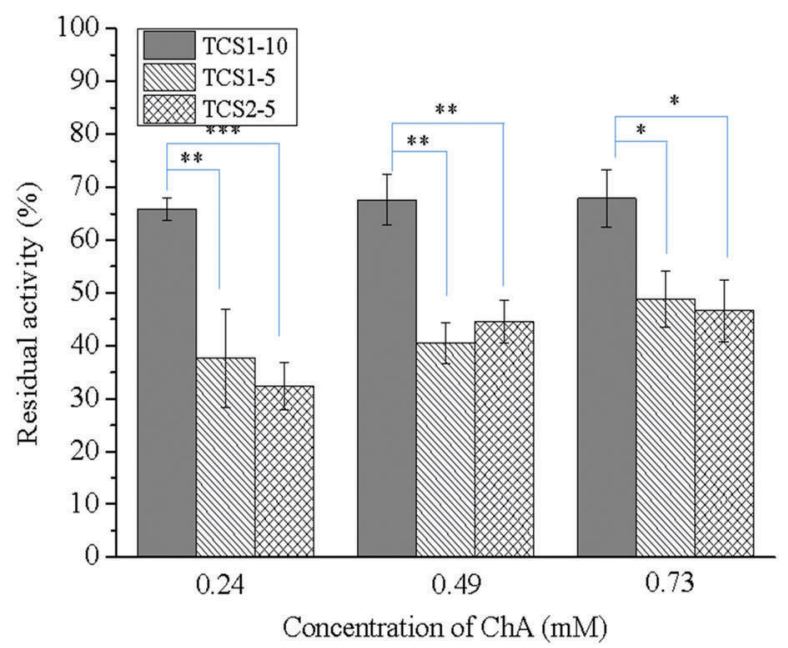

Fig. 8 Ex vivo inhibition of (A) MPO and (B) total MMPs in exudate from a venous leg ulcer by the hydrogels, depending on the degree of chitosan thiolation and the concentration of ChA. The results are reported as mean values $\pm \mathrm{SD}(n=3)$ and their statistical significance was calculated using one-way ANOVA $(p<0.05)$.

The increased inhibitory activity of the hydrogels upon decreasing the concentration of ChA can be explained by the larger amount of free thiol groups able to chelate $\mathrm{Zn}^{2+}$. The same tendency can be observed comparing the hydrogels prepared from TCS with increasing degree of thiolation while maintaining the ChA concentration constant (Fig. 8B).

\subsection{Biocompatibility of the hydrogels}

The main function of fibroblasts in the dermis is the synthesis of ECM. Fibroblasts, which are recruited in chronic wound repair, are more prone to senescence, and thus a biocompatible material is required in order to minimize the loss of their function. ${ }^{55}$ Human foreskin fibroblasts showed $80-95 \%$ viability after one-day incubation with the hydrogels (Fig. 9). Although the number of viable cells decreased to $70-85 \%$ after 7 days of incubation, most probably due to the sustained release of ChA, 
A

the hydrogels can be regarded as a biocompatible and efficient platform for treatment of chronic wounds.

\section{Conclusions}

In this paper, we report on the synthesis of hydrogels for chronic wound treatment from thiolated chitosan and the natural polyphenol ChA by using a green chemistry enzymatic approach. It was demonstrated for the first time that the naturally-based polyphenol ChA could serve as a crosslinking agent for the enzymatic synthesis of chitosan-based hydrogels.

The laccase catalyzed oxidation of this novel crosslinking agent allowed for fast gelation of the material by using concentrations in the micro-molar range, compared to our recently published work. ${ }^{22}$ The resulting hydrogels revealed tunable pore size, with respective swelling behavior depending on the $\mathrm{pH}$ of the media, the concentration of the crosslinking agent and the degree of thiolation of the polymer matrix. The antibacterial efficiency and the antioxidant and inhibitory effect of these hydrogels over deleterious wound enzymes defines them as potentially valuable dressing materials for chronic wound treatment.

\section{Materials and methods}

\subsection{Reagents and enzymes}

ChA (2,3-dicaffeoyl-t-tartaric acid), 5,5'-dithiobis-(2-nitrobenzoic acid) (Ellman's reagent), sodium phosphate mono- and dibasic, hydrochloric acid, 2,2'-azino-bis(3-ethylbenzothiazoline-6-sulfonic acid) (ABTS), phosphoric acid, boric acid, hydrogen peroxide, sodium acetate, sodium chloride, sodium hydroxide, acetic acid, 2-iminothiolane hydrochloride (Traut's reagent), L-cysteine, phosphate buffer saline (PBS), Bradford reagent (Coomasie Brilliant Blue G), 1,1-diphenyl-2-picrylhydrazyl (DPPH), Folin \& Ciocalteu's phenol reagent, sodium carbonate, 3,3',5,5'-tetramethylbenzidine, taurine, sodium iodide, and dimethyl sulfoxide were purchased from Sigma-Aldrich. Medical grade $15 \mathrm{kDa}$ fungal chitosan (degree of deacetylation $87 \%$ ) was provided by KitoZyme (Belgium).

Laccase (EC 1.10.3.2) Denilite II Base product (from Myceliophtora thermophila, $8.6 \mathrm{U} \mathrm{mg}^{-1}$, where $1 \mathrm{U}$ corresponds to the amount of enzyme which catalyzes the oxidation of $1 \mu \mathrm{mol}$ ABTS per min at pH 5.5 and $25{ }^{\circ} \mathrm{C}$ ) was provided by Novozymes (Denmark). Lysozyme (EC 3.2.1.17, $100000 \mathrm{U} \mathrm{mg}^{-1}$ where $1 \mathrm{U}$ corresponds to the amount of enzyme which decreases the absorbance at $450 \mathrm{~nm}$ by 0.001 per min at $\mathrm{pH} 7.0$ and $25{ }^{\circ} \mathrm{C}$ of Micrococcus luteus, ATCC 4698, as a substrate) was purchased from Sigma-Aldrich.

\subsection{Preparation of hydrogels}

Chitosan thiobutylamidine - the thiolated derivative of chitosan was synthesized by reacting the primary chitosan amino groups with Traut's reagent. ${ }^{29}$ Briefly, $1 \mathrm{~g}$ of chitosan was dissolved in $100 \mathrm{~mL} 1 \% \mathrm{CH}_{3} \mathrm{COOH}$ and the $\mathrm{pH}$ of the solution was adjusted to 6.5 with $5 \mathrm{M} \mathrm{NaOH}$. Chitosan batches with various degrees of thiolation (Table 1) were obtained depending on the amount of Traut's reagent. After stirring for $24 \mathrm{~h}$ in dark conditions, the solutions were dialyzed, once against $5 \mathrm{mM} \mathrm{HCl}$ with $1 \% \mathrm{NaCl}$, twice against $1 \mathrm{mM} \mathrm{HCl}$ with $1 \% \mathrm{NaCl}$, and finally against $1 \mathrm{mM} \mathrm{HCl}$ to remove the unreacted Traut's reagent. The chitosan derivative was lyophilized and stored at $4{ }^{\circ} \mathrm{C}$ under nitrogen atmosphere.

The amount of free thiol groups in each preparation was quantified using Ellman's reagent ${ }^{56}$ as follows: $2 \mathrm{mg}$ of the lyophilized TCS soaked in $1 \mathrm{~mL} 0.5 \mathrm{M}$ phosphate buffer $\mathrm{pH} 8$ was incubated with $1 \mathrm{~mL} 0.3 \mathrm{mg} \mathrm{mL}{ }^{-1}$ Ellman's reagent (dissolved in the same buffer) for $3 \mathrm{~h}$ under dark conditions; the mixtures were then centrifuged at $5000 \mathrm{rpm}$ for $5 \mathrm{~min}$ and the absorbance of the supernatant was measured at $450 \mathrm{~nm}$ with a microplate reader Infinite M200, Tecan (Austria). A calibration curve was built with L-cysteine standards using non-thiolated chitosan as a control.

The hydrogels were prepared in a similar way as described in our recently published article. ${ }^{22}$ Briefly, solutions containing 
$0.5 \mathrm{~mL} 7 \% \mathrm{w} / \mathrm{v}$ TCS with different degrees of thiolation, $0.05 \mathrm{~mL}$ laccase $\left(2.7 \mathrm{U} \mathrm{mL}^{-1}\right)$ and 100,67 and $33 \mu \mathrm{L} 2.25 \mathrm{mg} \mathrm{mL}^{-1} \mathrm{ChA}$ in $0.1 \mathrm{M}$ acetate buffer $\mathrm{pH} 5.5$, were prepared. After adjusting the volume of the solutions to $0.65 \mathrm{~mL}$ with acetate buffer, the mixtures were transferred to a 24 -well plate by a syringe outfitted with a $21 \mathrm{G}$ needle in order to maintain the same gel preparation conditions. Thereafter, the 24 -well plate was incubated for $2 \mathrm{~h}$ at the temperature of maximum laccase activity $\left(50{ }^{\circ} \mathrm{C}\right)$ to obtain the hydrogels (Table 2).

The phenolic content of the hydrogels was determined with $70 \mu \mathrm{L} 0.2 \mathrm{~N}$ Folin-Ciocalteu reagent, $120 \mu \mathrm{L} 20 \% \mathrm{w} / \mathrm{v} \mathrm{Na} \mathrm{NO}_{3}$ and $1.2 \mathrm{~mL}$ Milli-Q water per $1.4 \mathrm{mg}$ lyophilized sample. After incubating the mixtures for $1 \mathrm{~h}$ at room temperature under dark conditions, the absorbance at $765 \mathrm{~nm}$ of $300 \mu \mathrm{L}$ of each solution was measured. In order to evaluate the release of polyphenols from the hydrogels, $2 \mathrm{mg}$ of each lyophilized specimen was immersed in $500 \mu \mathrm{L}$ PBS buffer ( $\mathrm{pH}$ 7.4) for $24 \mathrm{~h}$ at $37^{\circ} \mathrm{C}$, and the amount of phenols in $400 \mu \mathrm{L}$ of supernatant was evaluated as described above. The results were expressed as a percentage from the initial concentration of ChA used for the preparation of the hydrogels.

\subsection{Rheological, structural and morphological characterization of the hydrogels}

The rheological properties of the hydrogels were monitored with an ARG2 rheometer (TA instruments, UK). A parallel plate geometry $(40 \mathrm{~mm})$ was used to analyze the samples. The crosslinking process was followed in the oscillatory mode $(0.1 \mathrm{~Hz})$ with $2 \%$ strain. The mixtures were placed onto the Peltier plate at $25{ }^{\circ} \mathrm{C}$, sealing the geometry with a solvent trap to prevent water evaporation, and the measurements were initiated after thermal equilibration to $50{ }^{\circ} \mathrm{C}$ (the temperature maximum of laccase activity). The crossover of the storage $\left(G^{\prime}\right)$ and the loss modulus $\left(G^{\prime \prime}\right)$ was used as a criterion for determination of the gelation point. The strain-dependent properties of a representative hydrogel prepared with the highest degree of thiolation and the highest concentration of ChA were studied at $1 \mathrm{~Hz}$ frequency and $0.1-1000 \%$ strain. The hydrogel sample was introduced to the Peltier plate at $37{ }^{\circ} \mathrm{C}$ and the measurement was initiated after adjustment of the gap to $1000 \mu \mathrm{m}$. The actual value of the hydrogel is the one taken in the viscoelastic region, where the hydrogels have shown linear and hence independent from the applied strain rheological behavior.

Raman spectra were acquired using a Raman spectrometer (Brüker MultiRam, Billerica, MA, USA) equipped with a Nd:YAG laser as the excitation source $(1064 \mathrm{~nm})$ with a spot size of $500 \mu \mathrm{m}$ and a liquid $\mathrm{N}_{2}$ cooled Ge diode detector. Opus 7.2 software was used for system control and to export data. The spectra were preprocessed using Unscrambler 10.3 software (Trondheim, Norway). The structural characteristics of the lyophilized samples were analyzed performing 512 scans at $4 \mathrm{~cm}^{-1}$ resolution over the $3600-200 \mathrm{~cm}^{-1}$ range with a $600 \mathrm{~mW}$ laser power.

The boiling-liquid nitrogen freezing method was used for sample preparation. A cross slice of the hydrogel was placed in the cryo-SEM holder with a clamp facility and introduced into a nitrogen slush at $-196{ }^{\circ} \mathrm{C}$. After freezing, the holder was transferred to the cryo-system (GATAN ALTO-1000) and kept frozen in vacuum conditions. A frozen pristine surface is obtained by cleaving the top of the sample slice and then, the sample is heated at $-80{ }^{\circ} \mathrm{C}$ for $15 \mathrm{~min}$ to sublimate frozen water and enhance the relief. The new surface was coated by Au-Pd sputtering $(10 \mathrm{~mA}$, $300 \mathrm{~s}$ ), introduced in the SEM (JEOL JSM-6510) chamber $\left(-190^{\circ} \mathrm{C}\right)$ and analyzed at $15 \mathrm{kV}$. Image 1.5 software was used to quantify the pore size of the samples.

The swelling equilibrium of the hydrogels was assessed after $24 \mathrm{~h}$ incubation at $37{ }^{\circ} \mathrm{C}$ in $\mathrm{PBS} \mathrm{pH}$ 7.4. The hydrogels were removed from the media every $1 \mathrm{~h}$ and their weight measured. After $6 \mathrm{~h}$ incubation, no further change of the hydrogels' weight was observed, considering that at this point the swelling equilibrium of the samples was reached. In order to determine their stability at physiological conditions, the hydrogels were subjected to enzymatic degradation in the presence of lysozyme (100000 $\mathrm{U} \mathrm{mL}^{-1}$ ). The medium was renewed and the hydrogels weighed once per day during six days. The results were compared to those acquired in an identical procedure without lysozyme. All experiments were carried out in five replicates and the average weight loss was calculated, according to eqn (1):

$$
\text { Weight loss }(\%)=100 \cdot\left(W_{\mathrm{s}}-W_{\text {lys }}\right) / W_{\mathrm{s}}
$$

where $W_{\mathrm{s}}$ is the weight of the swollen hydrogel at swelling equilibrium in PBS and $W_{\text {lys }}$ is the weight of the sample after lysozyme degradation.

The effect of the $\mathrm{pH}$ on the swelling ratio of the hydrogels was examined by immersion for $24 \mathrm{~h}$ at $37{ }^{\circ} \mathrm{C}$ in BrittonRobinson buffers with different $\mathrm{pH}$. After gentle blotting on a filter paper to remove the superficially adhered liquid, the weight of the swollen hydrogels was measured and the results were expressed as a percentage of the water uptake according to eqn (2):

$$
\mathrm{SW} \%=\left(\left(W_{\mathrm{s}}-W_{\mathrm{d}}\right) / W_{\mathrm{d}}\right) \cdot 100
$$

where $W_{\mathrm{s}}$ is the weight of the hydrogel in the swollen state, $W_{\mathrm{d}}$ is the weight of the lyophilized sample and SW\% is the percentage of water uptake. Five replicates of all samples were tested and the standard deviations were calculated.

\subsection{Ex vivo studies of the bioactivity of hydrogels}

Wound exudate was extracted from the dressing (UrgoClean ${ }^{\circledR}$, Urgo Medical) of a patient with a venous leg ulcer (Hospital de Terrassa (Spain)) as described elsewhere. ${ }^{22}$ The inhibitory activity of the hydrogels against MPO in the wound fluid was determined by quantifying the amount of taurine chloramine, produced by the $\mathrm{MPO} / \mathrm{H}_{2} \mathrm{O}_{2} / \mathrm{Cl}^{-}$system. Briefly, $750 \mu \mathrm{L}$ of $50 \mathrm{mM}$ PBS pH 6.5 with $200 \mathrm{mM} \mathrm{NaCl}$ and $6.67 \mathrm{mM}$ taurine were mixed with $100 \mu \mathrm{L} 1 \mathrm{mM} \mathrm{H}_{2} \mathrm{O}_{2}$ and $150 \mu \mathrm{L}$ wound fluid, previously diluted 10 times, in the presence of $2 \mathrm{mg}$ of each hydrogel sample. The samples were incubated for $2 \mathrm{~min}$ at $37{ }^{\circ} \mathrm{C}$ and the enzymatic reaction was stopped by addition of $33 \mu \mathrm{L} 1 \mathrm{mg} \mathrm{mL}^{-1}$ catalase solution. Then, $250 \mu \mathrm{L}$ of the detection

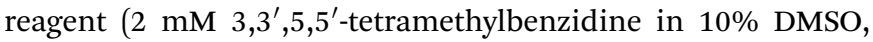
$100 \mu \mathrm{L} \mathrm{NaI}$ in $400 \mathrm{mM}$ acetate buffer $\mathrm{pH}$ 5.4) was added to the reaction mixture. After 5 min the amount of taurine chloramine 
generated during the enzymatic reaction was measured by recording the absorbance at $650 \mathrm{~nm}$. All measurements were carried out in triplicate and the results were expressed as a percentage of MPO inhibition, compared to controls without hydrogels, where the activity was considered as $100 \%$.

The inhibitory activity of the hydrogels against MMPs was assessed by using a fluorescently labeled gelatin substrate (EnzChek kit, ThermoFisher Scientific). The digestion of gelatin by MMPs leads to release of fluorescent peptides, and consequently increased fluorescence of the supernatant. Briefly, $1 \mathrm{mg}$ of lyophilized hydrogel species prepared from chitosan with different degrees of thiolation (TCS1-10, TCS1-5 and TCS2-5) and increasing concentrations of ChA $(0.24,0.49$ and $0.73 \mathrm{mM})$ were incubated with $400 \mu \mathrm{L}$ wound fluid, previously diluted 8 times with EnzChek buffer ( $\mathrm{pH} 7.5$ ) for $24 \mathrm{~h}$ at $37^{\circ} \mathrm{C}$. Thereafter, $100 \mu \mathrm{L}$ of each sample was transferred to a 96-well plate and was mixed with $80 \mu \mathrm{L}$ of the aforementioned buffer. The enzymatic reaction was initiated by addition of $20 \mu \mathrm{L}$ gelatin substrate (final concentration $25 \mu \mathrm{g} \mu \mathrm{L}^{-1}$ ) and the change of fluorescence was monitored at excitation/emission 493/528 nm. Wound fluid, incubated without hydrogel, served as a control and the MMP activity in that sample was considered as $100 \%$.

\subsection{Radical scavenging activity}

The antioxidant activity of the hydrogels was studied spectrophotometrically measuring the decrease of DPPH radical absorbance at $517 \mathrm{~nm}$. Briefly, $2 \mathrm{mg}$ of each hydrogel was incubated in $60 \mu \mathrm{M}$ DPPH solution in methanol at $37{ }^{\circ} \mathrm{C}$ under dark conditions for $30 \mathrm{~min}$. All measurements were performed in triplicate. Eqn (3) was used to calculate the antioxidant activity:

$$
\text { DPPH inhibition }(\%)=\left[1-\left(A / A_{0}\right)\right] \times 100
$$

where $A_{0}$ is the absorbance of the negative control (DPPH solution alone) and $A$ is the absorbance of $\mathrm{DPPH}$, incubated with the hydrogels.

\subsection{Cytotoxicity studies}

After sterilization under UV-light ( $1 \mathrm{~h}$ at $30 \mathrm{~W}$ power) the hydrogel samples (3 $\mathrm{mg}$ each) with different degrees of thiolation and different concentrations of ChA were put in contact with $1 \mathrm{~mL}$ of complete growth medium (DMEM) in a 24-well tissue culture-treated polystyrene plate, seeded with BJ-5ta cell line (human foreskin fibroblasts). The mixtures were placed in a $\mathrm{CO}_{2}$ humidified incubator at $37{ }^{\circ} \mathrm{C}$ for one or seven days. Afterwards, the hydrogels were removed and the growth media withdrawn. Media without hydrogels, where the cell viability was considered as $100 \%$, served as a negative control.

The previously seeded cells were put into contact with the withdrawn culture media and incubated for $24 \mathrm{~h}$ at $37{ }^{\circ} \mathrm{C}$ in a humidified atmosphere of $5 \% \mathrm{CO}_{2}$. The cells were further investigated for signs of toxicity using an AlamarBlue assay kit (AlamarBlue, Invitrogen). AlamarBlue was diluted in culture medium $(10 \% \mathrm{v} / \mathrm{v})$ and added to each well after aspirating the culture medium containing the samples. After incubation for $4 \mathrm{~h}$ at $37^{\circ} \mathrm{C}$, the absorbance of the cell culture was measured at $570 \mathrm{~nm}$, setting $600 \mathrm{~nm}$ as a reference wavelength.

\subsection{Antibacterial activity}

The Gram-positive $S$. aureus and the Gram-negative $P$. aeruginosa were grown on Baird-Parker and Cetrimide agar at $37{ }^{\circ} \mathrm{C}$ for $24 \mathrm{~h}$ and their optical density at $600 \mathrm{~nm}$ was measured. The bacterial suspensions were diluted to a concentration of $10^{6} \mathrm{CFU} \mathrm{mL}{ }^{-1}$. The hydrogel samples ( $3 \mathrm{mg}$ each) were incubated with $500 \mu \mathrm{L}$ of each bacterial suspension for 1 or $24 \mathrm{~h}$ at $37{ }^{\circ} \mathrm{C}$ and $450 \mathrm{rpm}$. Thereafter, different dilutions of the suspensions (prepared in sterile nutrient broth (NB)) were examined for $24 \mathrm{~h}$ growth of $S$. aureus and $P$. aeruginosa on Baird-Parker or Cetrimide agar, respectively. After counting the vital bacterial colonies, the ability of the hydrogels to reduce the bacterial growth was calculated, using eqn (4):

$$
\log \text { reduction }=\log _{10}(B / C)
$$

where $B$ and $C$ are the average number of bacterial colonies after $24 \mathrm{~h}$ incubation without (control sample) and with the hydrogel, respectively.

\subsection{Data analysis}

Replicate samples were used in each measurement, and all values are presented as mean values \pm the standard deviations (SD). The results were analyzed using Graph Pad Prism version 7.0c (Graph Pad Software, San Diego, CA, USA). Their statistical significance was determined using a one-way ANOVA followed by the Dunnett post hoc test or by the unpaired two-tailed Student's $t$-test method. $P$ values $\leq 0.05$ were considered statistically significant.

\section{Conflicts of interest}

There are no conflicts to declare.

\section{Acknowledgements}

This work was supported by the European project SKHINCAPS"SKin Healthcare by Innovative NanoCAPsuleS" (H2020-685909).

\section{Notes and references}

1 S. M. McCarty and S. L. Percival, Adv. Wound Care, 2013, 2, 438-447.

2 N. B. Menke, K. R. Ward, T. M. Witten, D. G. Bonchev and R. F. Diegelmann, Clin. Dermatol., 2007, 25, 19-25.

3 R. Brambilla, J. Hurlow, S. Landis and R. Wolcott, World Union Wound Heal. Soc., 2016, 1-6.

4 R. G. Frykberg and J. Banks, Adv. Wound Care, 2015, 4, 560-582.

5 G. Martin, V. Asensi, A. H. Montes, J. Collazos, V. Alvarez, J. A. Carton, F. Taboada and E. Valle-Garay, Sci. Rep., 2014, 4, 5002 .

6 T. N. Demidova-Rice, M. R. Hamblin and I. M. Herman, $A d v$ Ski. Wound Care, 2013, 25, 304-314.

7 S. E. Gomez-Mejiba, Z. Zhai, M. S. Gimenez, M. T. Ashby, J. Chilakapati, K. Kitchin, R. P. Mason and D. C. Ramirez, J. Biol. Chem., 2010, 285, 20062-20071. 
8 J. Arnhold and J. Flemmig, Arch. Biochem. Biophys., 2010, 500, 92-106.

9 K. Skórkowska-Telichowska, M. Czemplik, A. Kulma and J. Szopa, J. Am. Acad. Dermatol., 2013, 68, e117-e126.

10 A. Sood, M. S. Granick and N. L. Tomaselli, Adv. Wound Care, 2014, 3, 511-529.

11 T. Dai, M. Tanaka, Y.-Y. Huang and M. R. Hamblin, Expert Rev. Anti-Infect. Ther., 2011, 9, 857-879.

12 K. Yao, J. Li, F. Yao and Y. Yin, Chitosan-Based Hydrogels, Taylor \& Francis Group, LLC, 2012.

13 N. Bhattarai, J. Gunn and M. Zhang, Adv. Drug Delivery Rev., 2010, 62, 83-99.

14 A. Francesko, D. Soares da Costa, P. Lisboa, R. L. Reis, I. Pashkuleva and T. Tzanov, J. Mater. Chem., 2012, 22, 19438-19446.

15 P. Van Antwerpen, K. Z. Boudjeltia, S. Babar, I. Legssyer, P. Moreau, N. Moguilevsky, M. Vanhaeverbeek, J. Ducobu and J. Nève, Biochem. Biophys. Res. Commun., 2005, 337, 82-88.

16 V. Vargova, M. Pytliak and V. Mechirova, Matrix Metalloproteinase Inhibitors: Specificity of Binding and StructureActivity Relationships, Springer Basel AG, 2012.

17 A. I. Cañas and S. Camarero, Biotechnol. Adv., 2010, 28, 694-705.

18 J. Lee and C. F. Scagel, Front. Chem., 2013, 1, 40-41.

19 D. Zhu, N. Zhang, X. Zhou, M. Zhang, Z. Liu and X. Liu, RSC Adv., 2016, 7, 1363-1375.

20 D. Tousch, A. D. Lajoix, E. Hosy, J. Azay-Milhau, K. Ferrare, C. Jahannault, G. Cros and P. Petit, Biochem. Biophys. Res. Commun., 2008, 377, 131-135.

21 R. Bel-rhlid, N. Page, R. Fumeaux, T. Ho-dac, J. Chuat, J. L. Sauvageat and T. Raab, Agric. Food Chem., 2012, 60, 9236-9241.

22 I. Stefanov, S. Pérez-Rafael, J. Hoyo, J. Cailloux, O. O. Santana Pérez, D. Hinojosa-Caballero and T. Tzanov, Biomacromolecules, 2017, 18, 1544-1555.

23 Q. Xu, L. Guo, A. Sigen, Y. Gao, D. Zhou, U. Greiser, J. CreaghFlynn, H. Zhang, Y. Dong, L. Cutlar, F. Wang, W. Liu, W. Wang and W. Wang, Chem. Sci., 2018, 9, 2179-2187.

24 Q. Xu, A. Sigen, Y. Gao, L. Guo, J. Creagh-Flynn, D. Zhou, U. Greiser, Y. Dong, F. Wang, H. Tai, W. Liu, W. Wang and W. Wang, Acta Biomater., 2018, 75, 63-74.

25 G. Hermanson, Bioconjugate techniques, Elsevier Inc., 3rd edn, 2013.

26 G. Rocasalbas, A. Francesko, S. Touriño, X. FernándezFrancos, G. M. Guebitz and T. Tzanov, Carbohydr. Polym., 2013, 92, 989-996.

27 P. Petkova, A. Francesko and T. Tzanov, Eng. Life Sci., 2015, 15, 416-424.

28 S. Kaur and G. S. Dhillon, Crit. Rev. Microbiol., 2014, 40, 155-175.

29 A. Bernkop-Schnürch, Int. J. Pharm., 2003, 260, 229-237.

30 S. S. Wong and D. M. Jameson, Chemistry of Protein and Nucleic Acid Cross-Linking and Conjugation, Taylor \& Francis Group, 2nd edn, 2012.
31 C. B. Tang, W. G. Zhang, C. Dai, H. X. Li, X. L. Xu and G. H. Zhou, J. Agric. Food Chem., 2015, 63, 902-911.

32 H. T. Abdel-Mohsen, J. Conrad and U. Beifuss, Green Chem., 2014, 16, 90-95.

33 G. Socrates, Infrared and Raman characteristic group frequencies, 2004.

34 M. Romanelli, K. Vowden and D. Weir, Wounds Int., 2010, 1, 1-6.

35 J. Boateng, K. Matthews, H. Stevens and G. Eccleston, J. Pharm. Sci., 2007, 97, 2892-2923.

36 S. L. Percival, S. Mccarty, J. A. Hunt and E. J. Woods, Wound Repair Regen., 2014, 22, 174-186.

37 R. R. Watson, Polyphenols in Plants: Isolation, Purification and Extract Preparation, 2014.

38 B. Gyarmati, A. Nemethy and A. Szilagyi, Eur. Polym. J., 2013, 49, 1268-1286.

39 Advancis medical, Wound Essentials, 2012, 7, 1-3.

40 C. Dunnill, T. Patton, J. Brennan, J. Barrett, M. Dryden, J. Cooke, D. Leaper and N. T. Georgopoulos, Int. Wound J., 2017, 14, 89-96.

41 A. Schlernitzauer, C. Oiry, R. Hamad, S. Galas, F. Cortade, B. Chabi, F. Casas, L. Pessemesse, G. Fouret, C. FeilletCoudray, G. Cros, G. Cabello, R. Magous and C. WrutniakCabello, PLoS One, 2013, 8, e78788.

42 L. Thygesen, J. Thulin, A. Mortensen, L. H. Skibsted and P. Molgaard, Food Chem., 2006, 101, 74-81.

43 S. M. Deneke, Curr. Top. Cell. Regul., 2001, 36, 151-180.

44 A. Fujimoto, M. Inai and T. Masuda, Food Chem., 2013, 138, 1483-1492.

45 A. Heinzle, N. E. Papen-Botterhuis, D. Schiffer, K. P. Schneider, B. Binder, M. Schintler, I. K. Haaksman, H. B. Lenting, G. M. Guebitz and E. Sigl, Wound Repair Regen., 2013, 21, 482-489.

46 D. Ren, H. Yi, W. Wang and X. Ma, Carbohydr. Res., 2005, 340, 2403-2410.

47 E. F. Osserman and R. E. Canfield, Lysozyme, Academic Press, Inc., 1974.

48 J. Yang, M. A. Cohen Stuart and M. Kamperman, Chem. Soc. Rev., 2014, 43, 8271-8298.

49 L. Y. Zheng and J. F. Zhu, Carbohydr. Polym., 2003, 54, 527-530.

50 B. S. van der Veen, M. P. de Winther and P. Heeringa, Antioxid. Redox Signaling, 2009, 11, 2899-2937.

51 S. J. Klebanoff, J. Leukocyte Biol., 2005, 77, 598-625.

52 M. Díaz-GonzáLez, G. Rocasalbas, A. Francesko, S. Touriño, J. L. Torres and T. Tzanov, Biocatal. Biotransform., 2012, 30, 102-110.

53 I. Pastar, O. Stojadinovic, N. C. Yin, H. Ramirez, A. G. Nusbaum, A. Sawaya, S. B. Patel, L. Khalid, R. R. Isseroff and M. Tomic-Canic, Adv. Wound Care, 2014, 3, 445-464.

54 G. Schultz, Wounds Int., 2009, 1, 1-6.

55 R. T. Hannan, S. M. Peirce and T. H. Barker, ACS Biomater. Sci. Eng., 2018, 4, 1223-1232.

56 I. Bravo-Osuna, D. Teutonico, S. Arpicco, C. Vauthier and G. Ponchel, Int. J. Pharm., 2007, 340, 173-181. 